\title{
Effects of the Species of Female Parent and the Age of Ovules on Interspecific Hybrid Formation in Several Brassicas by Ovule Culture
}

\author{
Yukihiro FujIME*1, Surapong DUMRONGKITTIKULE*2, Guangyun MENG*2, \\ Nobuyuki OKUDA $^{* 2}$ and Toshiyuki MATSUI*2 \\ ${ }^{* 1}$ Faculty of Agriculture, Kyoto Prefectural University, Shimogamo, Sakyo, Kyoto 606-8522 Japan \\ ${ }^{* 2}$ Faculty of Agriculture, Kagawa University, Miki, Kagawa 761-0795 Japan
}

\begin{abstract}
To examine the effects of the species of the female parent and the age of ovules at ovule explantation after cross-pollination on interspecific hybrid formation among broccoli (Brassica oleracea L. var. italica Plen.), Chinese kale (B. oleracea L. var. alboglabra L. H. Bailey), broccoli $\operatorname{raab}(B . r a p a$ L.) and nabana (leafy rape: B. napus L.), an ovule culture was carried out. Ovules were explanted at 5 day intervals from 5 to 40 days after cross-pollination(DAP) and were cultured on MS medium supplemented with $0,0.1$ and $1 \mathrm{mg} / l$ of naphthalene acetic acid (NAA) and kinetin.

When ovules were explanted at 25 to $40 \mathrm{DAP}$, a higher rate of hybrid formation in several combinations of interspecific crossings was observed than in the earlier explantings. The percentage hybrid formation was dependent on selection of the female parent. When broccoli or Chinese kale was used as the female parent and broccoli raab was used as the pollen parent, hybrid plantlets were formed at higher percentages, regardless of the age of ovule at ovule explanting, compared with reciprocal combinations. When nabana or Chinese kale was used as the female parent and broccoli or nabana was used as the pollen parent, respectively, many hybrid plantlets were formed, regardless of the age of ovule at explanting, compared with reciprocal combinations. Higher concentrations of NAA in the medium may have suppressed hybrid formation.
\end{abstract}

Keywords : embryo rescue, brassicas, female parent, explanting time

\section{Introduction}

There is a demand for new leafy vegetables nowadays in Japan, whose edible parts are young inflorescence of, for example broccoli, Chinese kale or nabana or leafy rape, having many flower buds and thickened flower stalks or shoots. Though broccoli and nabana have many flower buds, they have a high chilling requirement for flower induction. Their cultures need cool seasons and their growing period is fairly long. On the other hand, Chinese kale and broccoli

Received 2 June 1999

Accepted 5 August 1999 raab, local leafy vegetables in southern Italy, have a low chilling requirement for flower induction and their growing period is shorter than that of broccoli and nabana. It is possible to grow them in any seasons, but they have fewer numbers of flower buds, and thin flower stalks.

There is a necessity to breed new leafy vegetables having low chilling requirements for flower induction and having early maturing characteristics by crossing these two groups. If these hybrids could have many flower buds and lower chilling requirements, it may be possible to grow them in Japan and in the tropics as well. A higher productivity might be expected than 
their parents, for they initiate flower buds earlier and have many flower buds. These new leafy hybrids might be also used in hydroponics under cover, because they have early maturity compared with parent lines and may be grown in year-round cultures.

It may be useful to raise interspecific hybrids by means of embryo or ovary culture ${ }^{12,16)}$, because these hybrid embryos abort at some stages in vivo. ${ }^{1}$ Matsuzawa ${ }^{9)}$ and Namai et al. ${ }^{12)}$ reported that the degree of success in raising interspecific hybrids depends on the combinations of species, cultivars, cultural methods and growing conditions. Bajaj et al. ${ }^{1)}$ reported that some of brassica species are difficult to hybridize due to certain crossability barriers such as abortion of the hybrid embryos. Many researchers ${ }^{2,5,7,9)}$ have tried to obtain interspecific hybrids between B. campestris and B. oleracea, but they reported that it was very difficult to produce them. Inomata ${ }^{6)}$ reported that in the interspecific crosses of $B$. campestris $\times B$. oleracea interspecific hybrids were formed successfully by ovary culture, but were not so successful in reciprocal crosses. Namai et $a l .{ }^{12)}$ also reported that ovary culture is a prominent technique in the cross of $B$. campestris $\times B$. oleracea, and that embryo culture is a good method in general, even in reciprocal crosses. The usefulness of ovule culture has rarely been reported for interspecific hybridization in cruciferous plants, other than by Takeshita et al. ${ }^{17)}$ and Hossain et al. ${ }^{4}$.

One of the present authors reported previously on a trial of raising new leafy hybrids in brassicas and showed the effectiveness of ovule culture ${ }^{8}$. The age of ovule at explantation and the selection of the female parent in cross pollination were unclear.

In this experiment to obtain interspecific hybrids among broccoli, Chinese kale, broccoli raab and nabana, the effects of selection of the female parent, age of ovules at explantation after cross-pollination and application of plant growth regulators to hybrid establishment were investigated.

\section{Materials and methods}

\section{Plant materials}

Seeds of broccoli (cv. Wase-midori), Chinese kale (cv. Wasekei-kairan), nabana (cv. Haru-ichiban) and broccoli raab (cv. Early) were placed in petri dishes and incubated at $23^{\circ} \mathrm{C}$ under 16 hours of fluorescent light (Homolux, National Co., $60 \mu \mathrm{mol} / \mathrm{m}^{2} / \mathrm{s}$ ). The germinated seeds were sown in seeding flats in October, 1997 and 1998 and were then transplanted into black plastic pots $(9 \mathrm{~cm}$ diameter $)$, they planted out into $1 / 5000$-a Wagner pots with mixed soil(soil 5 : sand 2 : vermiculite $2 \mathrm{v} / \mathrm{v}$ ) when the $3 \mathrm{rd}$ leaf and 8 th leaf were unfolded, respectively. The plants were cultivated in a greenhouse with standard management.

Experiment 1. Effects of the species of female parent and the age of ovules at explantation on interspecific hybrid formation

Young flower buds of the female parent were emasculated and covered with head bags one day before anthesis, and were cross-pollinated by hand the next morning.

\section{Cross pollination and excising of ovules}

Cross-pollinations were made in the following eight combinations; broccoli $\times$ broccoli raab, broccoli $\times$ nabana, Chinese kale $\times$ broccoli raab, Chinese kale $\times$ nabana and their reciprocal combinations. After cross-pollination, ovaries were sampled eight times at 5 day intervals over 40 days. Sampled ovaries were scrubbed with soap and were washed under running tap water. Then the ovaries were sterilized by soaking in $70 \%$ ethyl alcohol for 30 seconds and subsequently in $1.5 \% \mathrm{NaOCl}$ solution for 10 minutes and were soaked three times in sterile water for $10 \mathrm{~min}$ utes. The ovules were excised from sampled ovaries and their color and shapes were observed. Size of the ovules was measured by stereo-microscopy. Mean length and width of ovules in each combination at different explanting times were analyzed statistically by the chi-square test.

\section{Cultural condition of ovules in vitro}

The excised ovules were explanted on Murashige \& Skoog medium(1962) supplemented with $0.1 \mathrm{mg} / l$ NAA, $0.1 \mathrm{mg} / l$ kinetin, $30 \mathrm{~g} / l$ sucrose and $2 \mathrm{~g} / l$ gellan gum. The medium was adjusted to $\mathrm{pH}$ 5.75. A single ovule was explanted in $10 \mathrm{~m} l$ of medium in a test tube $(15 \mathrm{~cm}$ height $\times 2 \mathrm{~cm}$ diameter $)$ and 20 explants were used per treatment. The explanted ovules were 
cultured at $23^{\circ} \mathrm{C}$ under 16 hours of fluorescent light (Homolux, National Co., $60 \mu \mathrm{mol} / \mathrm{m}^{2} / \mathrm{s}$ ). Plantlet formation was observed every week after explantation for nine weeks. Whenever both shoots and roots were observed, it was considered that a plantlet was established. The number of established plantlets in each treatment was analyzed statistically by the chisquare test.

\section{Experiment 2. Effects of combinations of NAA and kinetin treatments on interspecific hybrid formation}

Ovaries cross-pollinated in eight combinations; broccoli $\times$ broccoli raab, broccoli raab $\times$ broccoli, broccoli $\times$ nabana, nabana $\times$ broccoli, Chinese kale $\times$ broccoli raab, broccoli raab $\times$ Chinese kale, Chinese kale $\times$ nabana and nabana $\times$ Chinese kale, were dissected at $40,5,25,30,30,15,30$ and 5 days after cross-pollination, respectively. The dates were determined based on the results of Experiment 1 . The sampled ovaries were sterilized as indicated in Experiment 1. The ovules in each cross-pollination were excised from the ovaries and were explanted on MS medium supplemented with nine combinations of 0, 0.1 and $1 \mathrm{ppm} \mathrm{NAA}$ and kinetin. A single ovule was explanted in $10 \mathrm{~m} l$ of medium in a test tube and 20 explants were used per treatment. The explanted ovules were cultured at $23^{\circ} \mathrm{C}$ under 16 hours of fluores- cent light. Plantlet formation was observed every week for eight weeks. Plantlet formation in each crossing at different combinations of NAA and kinetin was measured and analyzed statistically by the chisquare test ${ }^{19)}$.

\section{Results}

Experiment 1. Effects of the species of female parent and the age of ovules on interspecific hybrid formation

\section{Size and shape of ovules}

The size of ovules at different explantation times in various cross-combinations was significantly different (Table 1). When broccoli was used as the female parent and broccoli raab or nabana was used as the pollen parent, explanted ovules became significantly larger at 20 and 25 DAP and became smaller thereafter than the earlier explantings. In the reciprocal combinations, explanted ovules were larger at 10 and $15 \mathrm{DAP}$ and also became smaller at $20 \mathrm{DAP}$ and later. When broccoli was used as the female parent, the size of ovules in those combinations was larger than that of the reciprocal combinations at any time of explantation. Shape and color changes in ovules at different explanting ages showed similar changes in each combination (Table 2). In the above mentioned combinations, shrinkage of ovules and surface color

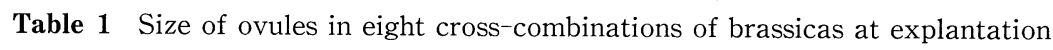

\begin{tabular}{|c|c|c|c|c|c|c|c|c|c|c|}
\hline \multirow{3}{*}{ Cross } & \multirow{3}{*}{ Position } & \multicolumn{8}{|c|}{ Ovule size $(\mathrm{mm})$} & \multirow[b]{3}{*}{ Chi-square } \\
\hline & & \multicolumn{8}{|c|}{ Ovule age at explanting (DAP) } & \\
\hline & & 5 & 10 & 15 & 20 & 25 & 30 & 35 & 40 & \\
\hline Broccoli $\times$ Broccoli raab & Width & 0.55 & 1.18 & 1.39 & 1.53 & 1.49 & 1.23 & 0.97 & 0.99 & $.63^{* *}$ \\
\hline$($ B. oleracea $\times$ B. rapa $)$ & Length & 0.72 & 1. 60 & 1.84 & 1.9 & 1.92 & 1.67 & 1. 35 & 1.52 & $.7^{* *}$ \\
\hline \multirow[t]{2}{*}{ Broccoli raab $\times$ Broccoli } & Width & 0.44 & 0.83 & 0.52 & 0.49 & 0.44 & 0.46 & 0.49 & 0.47 & $.23^{* *}$ \\
\hline & Length & 0.68 & 1.07 & 0.7 & 0.61 & 0.58 & 0.61 & 0.60 & 0.58 & $28^{* *}$ \\
\hline Nabana $\times$ Broccoli & Width & 0.52 & 0.81 & 0.64 & 0.62 & 0.58 & 0.65 & 0.60 & 0.59 & $.08^{* *}$ \\
\hline (B. napus $\times B$. oleracea) & Length & 0.63 & 1.18 & 0.98 & 0.92 & 0.89 & 0.93 & 0.80 & 0.85 & $19^{* *}$ \\
\hline \multirow[t]{2}{*}{ Broccoli × Nabana } & Width & 0.5 & 0.98 & 1.34 & 1.52 & 1.45 & 1.21 & 1.10 & 1.05 & $.64^{* *}$ \\
\hline & Length & 0.6 & 1.21 & 1.74 & 1.83 & 1.92 & 1. 65 & 1.55 & 1. 40 & $.85^{* *}$ \\
\hline \multirow{4}{*}{$\begin{array}{l}\text { Chinese kale } \times \text { Broccoli raab } \\
(B \text {. oleracea } \times \text { B. rapa }) \\
\text { Broccoli raab } \times \text { Chinese kale }\end{array}$} & Width & 0.62 & 1. 28 & 1.16 & 1.58 & 1. 43 & 1. 48 & 1.38 & 1.57 & $.52^{* *}$ \\
\hline & Length & 0.72 & 1. 48 & 1.37 & 1.69 & 1. 74 & 1. 69 & 1. 72 & 1.90 & $.62^{* *}$ \\
\hline & Width & 0.3 & 0.76 & 0.55 & 0.56 & 0.45 & 0.37 & 0.52 & 0.48 & $.27^{* *}$ \\
\hline & Length & 0.43 & 1.00 & 0.73 & 0.76 & 0.61 & 0.53 & 0.65 & 0.63 & $30^{* *}$ \\
\hline \multirow{4}{*}{$\begin{array}{l}\text { Chinese kale } \times \text { Nabana } \\
(B \text {. oleracea } \times B . \text { napus }) \\
\text { Nabana } \times \text { Chinese kale }\end{array}$} & Width & 0.86 & 1. 26 & 1.33 & 1.65 & 1. 52 & 1.52 & 1.60 & 1.53 & $.33^{* *}$ \\
\hline & Length & 0.96 & 1.35 & 1. 49 & 1.80 & 1.65 & 1.70 & 1.80 & 1.79 & $.36^{* *}$ \\
\hline & Width & 0.71 & 0.78 & 0.61 & 0.59 & 0.67 & 0.59 & 0.55 & 0.52 & $08^{* *}$ \\
\hline & Length & 1.05 & 1.25 & 1.07 & 0.90 & 0.90 & 0.79 & 0.88 & 0.79 & $.18^{* *}$ \\
\hline
\end{tabular}

** significant at $p<0.01(\mathrm{df}=1)$ 
Table 2 Changes of color and shape of ovules in eight cross-combinations of brassicas at explantation

\begin{tabular}{|c|c|c|c|c|c|c|c|c|c|}
\hline \multirow{3}{*}{ Cross } & \multirow{3}{*}{$\begin{array}{l}\text { Shape } \\
\text { and color }\end{array}$} & \multicolumn{8}{|c|}{ Shape and color of ovules } \\
\hline & & \multicolumn{8}{|c|}{ Ovule age at explanting (DAP) } \\
\hline & & 5 & 10 & 15 & 20 & 25 & 30 & 35 & 40 \\
\hline \multirow{4}{*}{$\begin{array}{l}\text { Broccoli } \times \text { Broccoli raab } \\
(\text { B. olerace } \times \text { B. rapa }) \\
\text { Broccoli raab } \times \text { Broccoli }\end{array}$} & Shrinkage & - & - & - & - & - & $H$ & H & $H$ \\
\hline & Color & $\mathrm{G}$ & G & $\mathrm{G}$ & G & $\mathrm{B}$ & $\mathrm{B}$ & $\mathrm{B}$ & $\mathrm{B}$ \\
\hline & Shrinkage & - & - & H & m & H & H & H & 世 \\
\hline & Color & $\mathrm{G}$ & G & $\mathrm{G}$ & $\mathrm{B}$ & $\mathrm{B}$ & $\mathrm{B}$ & $\mathrm{B}$ & $\mathrm{B}$ \\
\hline \multirow{4}{*}{$\begin{array}{l}\text { Nabana } \times \text { Broccoli } \\
(B . \text { napus } \times \text { B. oleracea }) \\
\text { Broccoli } \times \text { Nabana }\end{array}$} & Shrinkage & - & - & H & $H$ & $H$ & $H$ & $H$ & H \\
\hline & Color & $\mathrm{G}$ & $\mathrm{G}$ & $B$ & $\mathrm{~B}$ & $\mathrm{~B}$ & B & $\mathrm{B}$ & B \\
\hline & Shrinkage & - & - & - & - & $H$ & $H$ & H & $H$ \\
\hline & Color & G & G & $\mathrm{G}$ & G & $\mathrm{B}$ & $\mathrm{B}$ & $\mathrm{B}$ & B \\
\hline \multirow{4}{*}{$\begin{array}{l}\text { Chinese kale } \times \text { Broccoli raab } \\
(B \text {. oleracea } \times \text { B. rapa }) \\
\text { Broccoli raab } \times \text { Chinese kale }\end{array}$} & Shrinkage & - & - & - & - & + & + & + & + \\
\hline & Color & G & $\mathrm{G}$ & G & $\mathrm{B}$ & $\mathrm{B}$ & B & B & B \\
\hline & Shrinkage & - & - & - & H & H & H & H & 世 \\
\hline & Color & G & $\mathrm{G}$ & $\mathrm{G}$ & $\mathrm{B}$ & $\mathrm{B}$ & $\mathrm{B}$ & $\mathrm{B}$ & $\mathrm{B}$ \\
\hline \multirow{4}{*}{$\begin{array}{l}\text { Chinese kale } \times \text { Nabana } \\
(B . \text { oleracea } \times B . \text { napus }) \\
\text { Nabana } \times \text { Chinese kale }\end{array}$} & Shrinkage & - & - & - & + & + & + & + & + \\
\hline & Color & $\mathrm{G}$ & G & $\mathrm{G}$ & $\mathrm{B}$ & $\mathrm{B}$ & $\mathrm{B}$ & $\mathrm{B}$ & B \\
\hline & Shrinkage & - & - & H & HI & H & H & HI & HI \\
\hline & Color & G & G & $\mathrm{B}$ & $\mathrm{B}$ & $\mathrm{B}$ & $\mathrm{B}$ & $\mathrm{B}$ & $\mathrm{B}$ \\
\hline
\end{tabular}

Shrinkage of ovule: - no; + slight; + moderate; +m severe

Color of ovule: $\mathrm{G}$ green; $\mathrm{B}$ brown

change from green to brown occurred later than in reciprocal combinations.

When Chinese kale was used as the female parent and broccoli raab or nabana was used as the pollen parent, explanted ovules became larger until 40 DAP.
In the reciprocal combinations, explanted ovules were larger at 10 and $15 \mathrm{DAP}$, and were smaller at $20 \mathrm{DAP}$ and later. The size of ovules in the former combinations was larger than that of the reciprocal combinations at any time of explanting. In the former combi-

Table 3 Effects of the species of the female parent and age of ovules at explantation on interspecific plantlet formation in brassicas by ovule culture

\begin{tabular}{|c|c|c|c|c|c|c|c|c|c|}
\hline \multirow{3}{*}{ Cross } & \multicolumn{8}{|c|}{ Plantlet formation(\%) } & \multirow[b]{3}{*}{ Chi-Square ${ }^{1}$} \\
\hline & \multicolumn{8}{|c|}{ Ovule age at explanting (DAP) } & \\
\hline & 5 & 10 & 15 & 20 & 25 & 30 & 35 & 40 & \\
\hline $\begin{array}{l}\text { Broccoli } \times \text { Broccoli raab } \\
(\text { B. oleracea } \times \text { B. rapa })\end{array}$ & - & 15 & 25 & 10 & 30 & 25 & 20 & 40 & $10.39 * *$ \\
\hline Broccoli raab $\times$ Broccoli & 10 & - & 5 & - & 5 & - & - & - & $8^{* *}$ \\
\hline $\begin{array}{l}\text { Nabana } \times \text { Broccoli } \\
(B . \text { napus } \times \text { B. oleracea })\end{array}$ & - & - & 20 & 15 & 15 & 30 & 20 & 15 & $10.04^{* *}$ \\
\hline Broccoli $\times$ Nabana & - & - & - & 5 & 5 & 5 & - & - & $5^{*}$ \\
\hline $\begin{array}{l}\text { Chinese kale } \times \text { Broccoli raab } \\
(\text { B. olerace } \times \text { B. rapa })\end{array}$ & - & 20 & 10 & - & 35 & 45 & 15 & 35 & $20^{* *}$ \\
\hline Broccoli raab $\times$ Chinese kale & - & 5 & 10 & - & - & - & - & - & $10.33^{* *}$ \\
\hline $\begin{array}{l}\text { Chinese kale } \times \text { Nabana } \\
(B . \text { oleracea } \times \text { B. napus })\end{array}$ & - & - & 5 & - & 25 & 40 & 25 & 30 & $23.32 * *$ \\
\hline Nabana $\times$ Chinese kale & 15 & - & - & 5 & - & - & - & 5 & $12.6^{* *}$ \\
\hline
\end{tabular}


nations, shrinkage and surface color change occurred later than in reciprocal combinations.

\section{Hybrid plantlet formation}

When broccoli or Chinese kale was used as the female parent and broccoli raab was used as the pollen parent, plantlet formation occurred at different ovule ages (Table 3 ). Higher percentages (10 to $40 \%$ ) of plantlet formation were observed for the combination of broccoli $\times$ broccoli raab at 10 to $40 \mathrm{DAP}$, compared with the reciprocal combination. Only 5 and $10 \%$ plantlet formation occurred in the reciprocal combination when ovules were explanted at 5, 15 and 25 DAP. Ten to $45 \%$ plantlet formation was observed in the combination of Chinese kale $\times$ broccoli raab at 10 to 40 DAP. Only 5 and 10\% plantlet formation occurred in the reciprocal combination when ovules were explanted at 10 and 15 DAP respectively.

When nabana or Chinese kale was used as the female parent and broccoli or nabana was used as the pollen parent, there was a significant difference in plantlet formation at different ovule ages. In the combination of Chinese kale $\times$ nabana, 5 to $40 \%$ plant let formation was observed when ovules were explanted at 15 to 40 DAP. Only 5 to $15 \%$ plantlet formation occurred in the reciprocal combination when the ovules were explanted at 5, 20 and 40 DAP. Fifteen to $30 \%$ plantlet formation occurred at 15 to $40 \mathrm{DAP}$ in the combination of nabana $\times$ broccoli when ovules were explanted at 15 to 40 DAP. Only $5 \%$ plantlet formation was observed in the reciprocal combination when the ovules were explanted at 20 to 30 DAP.

Experiment 2. Effects of combinations of NAA and kinetin treatments on interspecific hybrid formation

When broccoli or Chinese kale was used as the female parent and broccoli raab was used as the pollen

Table 4 Effects of combinations of NAA and kinetin treatments on interspecific plantlet formation in several brassicas in ovule culture

\begin{tabular}{|c|c|c|c|c|c|}
\hline \multirow{3}{*}{ Cross } & \multirow{3}{*}{$\operatorname{Kinetin}(\mathrm{mg} / l)$} & \multirow{2}{*}{\multicolumn{3}{|c|}{$\begin{array}{c}\text { Plantlet formation }(\%) \\
\text { NAA }(\mathrm{mg} / l)\end{array}$}} & \multirow{3}{*}{ Chi-square $^{1 /}$} \\
\hline & & & & & \\
\hline & & 0 & 0.1 & 1 & \\
\hline Broccoli $\times$ Broccoli raab & 0 & 15 & - & 5 & $16.53^{* *}$ \\
\hline \multirow[t]{2}{*}{ (B. oleracea $\times$ B. rapa $)$} & 0.1 & 5 & 5 & 5 & \\
\hline & 1 & 30 & 25 & 5 & \\
\hline \multirow[t]{3}{*}{ Broccoli raab $\times$ Broccoli } & 0 & - & - & - & $8^{* *}$ \\
\hline & 0.1 & - & - & - & \\
\hline & 1 & 5 & - & - & \\
\hline Nabana $\times$ Broccoli & 0 & 5 & - & - & $8^{* *}$ \\
\hline \multirow[t]{2}{*}{ (B. napus $\times$ B. oleracea) } & 0.1 & - & - & - & \\
\hline & 1 & - & - & - & \\
\hline \multirow[t]{3}{*}{ Broccoli $\times$ Nabana } & 0 & - & - & - & - \\
\hline & 0.1 & - & - & - & \\
\hline & 1 & - & - & - & \\
\hline Chinese kale $\times$ Broccoli raab & 0 & 40 & 40 & 40 & $7.97^{* *}$ \\
\hline \multirow{2}{*}{ (B. oleracea $\times$ B. rapa) } & 0.1 & 60 & 35 & 15 & \\
\hline & 1 & 45 & 20 & 30 & \\
\hline \multirow[t]{3}{*}{ Broccoli raab $\times$ Chinese kale } & 0 & 25 & 20 & 15 & 4. $2^{\mathrm{ns}}$ \\
\hline & 0.1 & 15 & 10 & 5 & \\
\hline & 1 & 25 & 20 & 15 & \\
\hline Chinese kale $\times$ Nabana & 0 & 5 & 15 & - & 17. $47^{* *}$ \\
\hline \multirow[t]{2}{*}{ (B. oleracea $\times$ B. napus) } & 0.1 & 10 & 5 & 10 & \\
\hline & 1 & 35 & 15 & - & \\
\hline \multirow[t]{3}{*}{ Nabana $\times$ Chinese kale } & 0 & - & - & - & - \\
\hline & 0.1 & - & - & - & \\
\hline & 1 & - & - & - & \\
\hline \multicolumn{6}{|c|}{$\begin{array}{l}-: \text { no plantlet formation } \\
* \quad \text { significant at } p<0.05(\mathrm{df}=1),,^{* *} \mathrm{si} \\
1 / \quad \text { Chi-square of plantlet formation an } \\
\quad \text { crossing }\end{array}$} \\
\hline
\end{tabular}


parent, a high rate of plantlet formation occurred compared with the reciprocal combination, as in Experiment 1(Table 4). In the combination of Chinese kale $\times$ nabana, a high rate of plantlet formation also occurred compared with the reciprocal combination. Although the effect of kinetin concentration on plantlet formation was not clear, there was a tendency for higher concentrations of NAA to suppress plantlet formation in the combinations of broccoli $\times$ broccoli raab, Chinese kale $\times$ broccoli raab, broccoli raab $\times$ Chinese kale and Chinese kale $\times$ nabana.

\section{Discussion}

\section{Hybrid plant formation by ovule culture}

Takeshita et al. ${ }^{17)}$, Hossain et al. ${ }^{4)}$ and Kudou et $a l{ }^{8)}$ reported that ovule culture was a method superior to embryo and ovary cultures in terms of formation rate of brassica hybrids and in the handling of ovule explantation when $B$. oleracea was used as the female parent, compared with the reciprocal combinations. In the present experiment many interspecific hybrids were obtained by ovule culture when broccoli or Chinese kale, belonging to $B$. oleracea, was used as the female parent, compared with the reciprocal combinations.

Matsuzawa ${ }^{9)}$ and Namai et $a l .{ }^{12)}$ reported that the production rate of brassica hybrids was not the same with reciprocal crossings, though no reason for this was suggested in their reports. There are contradictory reports about the role of female parent in the hybridization of $B$. oleracea $\times B$. campestris. It is reported that more hybrids were obtained in the cross of $B$. campestris $\times B$. oleracea than by the reciprocal $\operatorname{cross}^{3,6,12)}$. On the other hand there are several reports that higher production rates of hybrids were obtained in the cross of $B$. oleracea $\times B$. campestris, but not in reciprocal crossings $s^{4,8,11,14,17)}$.

Namai et $a l .{ }^{12)}$ reviewing the interspecific hybridization breeding in Japan, reported that the rate of hybrid formation depends on the plant materials used such as embryo, ovule or ovary in the crossing of $B$. campestris $\times B$. oleracea. He stated also that embryo culture is a good method in general, and it is especially effective in crossing of $B$. oleracea $\times B$. campestris while ovary culture is a superior technique in crossing $B$. campestris $\times B$. oleracea. Hossain et al. ${ }^{4)}$ reported that ovule culture was more effective when $B$. oleracea was used as the female parent.

The above-quoted reports may be rearranged as follows according to culture methods in vitro. For hybridization of $B$. oleracea $\times B$. campestris, when $B$. oleracea or/and $B$. campestris is used as the female parent, it is better to use embryo culture $e^{4,11,12,14)}$; for hybridization when $B$. oleracea or $B$. campestris is used as the female parent, the ovule culture or ovary culture are suitable, respectively ${ }^{4,6,8,12,17,18}$. In the present experiment, the usefulness of broccoli or Chinese kale as the female parent in interspecific hybridization by ovule culture was clearly indicated, and it was in accordance with the findings reported by Takeshita et $a l .{ }^{17)}$, Kudou et $a l{ }^{8}{ }^{8}$, Hossain et $a l .^{4)}$ and Namai et $a l .{ }^{12)}$.

\section{Age of embryos for explantation}

In this experiment it was verified that 25 to $40 \mathrm{DAP}$ were good excising and explantation ages for embryo rescue in brassica hybridization. The findings agreed with a previous report ${ }^{8)}$. The proper explantation age differed for the combinations of crossing. When broccoli or Chinese kale was used as the female parent, the appropriate age was later than that of reciprocal combinations. Takeshita et al. ${ }^{17)}$ also reported that a higher hybrid formation rate was obtained at 22 to 25 DAP. However, only a few hybrids were formed at earlier explantations in reciprocal combinations. The reason for the optimum explanting ages differing in reciprocal crosses was that the growth of hybrid embryos was somehow affected by the female parent. There are some reports that the growth of embryos is affected by the female parent ${ }^{1,9,18)}$. Kudou et al. ${ }^{8)}$ and Nishi ${ }^{13)}$ reported that when $B$. campestris was used as the female parent, hybrid embryos grew faster in culture than crossings where $B$. oleracea was used as the female parent.

In ovary culture ${ }^{4,14)}$ young ages of embryos such as 4 to 8 DAP were used; in ovule culture ${ }^{8,17)}$ early ages of embryos such as 22 to 25 DAP were used, and in embryo culture ${ }^{4,13)}$ more developed embryos such as 22 to 40 DAP were used. The optimum explantation ages in the present experiment are similar to the 
findings of these reports. A slight discrepancy may be due to the differences of used cultivars and environmental conditions as Namai et al. ${ }^{12)}$ reported.

\section{Change in size and color of ovule}

An increase of ovule size in the crosses of broccoli $x$ broccoli raab, Chinese kale $\times$ broccoli raab and Chinese kale $\times$ nabana continued longer, and their shrinkage and color changes occurred later than in their reciprocal crossings. Yamagishi et al. ${ }^{18)}$ reported also that the hybrid embryos continued to develop longer when $B$. oleracea was used as the female parent, than when $B$. campestris was used as the female parent.

When broccoli and Chinese kale were used as the female parent, the ovules continued to grow, and shrinkage and color changes occurred later. Those ovules continued to develop, and the embryos developed without abortion or abnormalities. Larger and more developed ovules were suitable for excision and culturing for hybrid formation. The ovules did not grow longer in the reciprocal crossings and embryo abortion or abnormal embryo development took place earlier. Thus, it was concluded that when broccoli and Chinese kale was used as the female parent, since ovules were more developed and larger compared with reciprocal crosses, ovules were easier to excise without damage.

In the crossing of broccoli $\times$ nabana, lower numbers of hybrid plantlets were formed, compared with reciprocal crossings. Whereas ovules continued to increase in size longer, shrinkage and changes of color occurred later than in the reciprocal crossings, and establishment of a greater number of hybrid plantlets was expected, lower numbers of hybrid plantlets were formed.

\section{Effects of $N A A$ and kinetin}

Higher concentrations of NAA are thought to have suppressed hybrid formation in the present experiment. The supplementation of NAA and 2, 4-D to MS medium was found to inhibit shoot formation in brassica explants in vitro. ${ }^{10}$. The presence of auxin in the medium reduced the cell proliferation of $B$. alboglabra explants ${ }^{15)}$. In interspecific crossings, an inhibitory effect of NAA was not clear, but the effect may depend on the vigor of explants and condition of mother plants.

In this experiment the effects of species of the female parent in crossing, and the age of ovule at explantation were confirmed. In a previous report ${ }^{8)}$ one of the authors showed that the plant growth characteristics of hybrids were intermediates of their parent lines. Morphological investigations on early embryo development are in progress.

\section{References}

1) Bajaj, Y. P. S., Mahajan, S. K. and Labana, K. S. : Interspecific hybridization of Brassica napus and $B$. juncea through ovary, ovule and embryo culture, Euphytica, 35 : 103-109(1986)

2) Hegazi, H. H. and Matsubara, S. : Plant regeneration from hypocotyl callus of intergeneric and interspecific hybrids between radish $(R a$ phanus sativus L. daikon and radicula groups), cabbage (Brassica oleracea L. capitata group) and Chinese cabbage (B. campestris L. pekinensis group), J. Japan. Soc. Hort. Sci., 60 (2) : 369-377 (1991)

3) Hossain, M. M., Inden, H. and Asahira, T. : Production of interspecific hybrids in Brassica for the tropics, II. Effects of media on the interspecific embryo and ovary development in vitro between $B$. campestris and $B$. oleracea, Abstr. Jpn. Soc. Hort. Sci., Autumn Meet. : 230231 (1987)

4) Hossain, M. M., Inden, H. and Asahira, T. : Interspecific hybrids between Brassica campestris L. and B. oleracea L. through embryo and ovary culture, Mem. Coll. Agric., Kyoto Univ., $135: 21-30$ (1989)

5) Hossain, M. M., Inden, H. and Asahira, T. : Seed vernalized interspecific hybrids through in vitro ovule culture in Brassica, Plant Sci., $68: 95$ -102(1990)

6) Inomata, N.: Production of interspecific hybrids between Brassica campestris and Brassica oleracea by culture in vitro of excised ovaries, I. Effects of yeast extract and casein hydrolysate on the development of excised ovaries, Japan. J. Breed., 27 (4) : 295-304 (1977)

7) Inomata, N.: Production of interspecific hybrids in Brassica campestris $\times$ B. oleracea by culture in vitro of excised ovaries, II. Development of excised ovaries on various culture media, Japan. J. Breed., 29 : 115-120 (1979)

8) Kudou, R., Fujime, Y. and Fukada, N. : Raising of Brassica interspecific hybrids by embryo culture, Acta Horticulturae, 392 : 87-95(1995)

9) Matsuzawa, Y.: Studies on the interspecific hybridization in genus Brassica, I. Effects of 
temperature on the development of hybrid embryo and the improvement of crossability by ovary culture in interspecific cross, B. campestris $\times$ B. oleracea, Japan. J. Breed., 28(3) : 186196(1978) (In Japanese with English summary)

10) Murata, M. and Orton, T. J. : Callus initiation and regeneration capacities in Brassica species, Plant Cell, Tissue and Organ Culture, 11 : 111123(1987)

11) Nagano, K. : Senposai no ikusei keika to sanchi keisei, Bio Horti, 1 : 18-19(1989) (In Japanese)

12) Namai, H., Sarashima, M. and Hosoda, T.: Interspecific and intergeneric hybridization breeding in Japan, In: Tsunoda, S., Hinata K. and Gómes-Campo C.(Eds.), Brassica crops and wild allies, Japan Scientific Societies Press, Tokyo, pp. 191-201 (1980)

13) Nishi, S. : Differentiation of brassica crops in Asia and the breeding of 'Hakuran' a newly synthesized leafy vegetables, In: Tsunoda, S., Hinata K. and Gómes-Campo C.(Eds.), Brassica crops and wild allies, Japan Scientific Societies Press, Tokyo, pp. 133-150(1980)
14) Nishi, S.: Haibaiyo no genjo to hakuran, Bio Horti, $1:$ 9-14 (1989) ( In Japanese)

15) Pua, E. C., Trinh, T. H. and Chua, N. H. : High frequency plant regeneration from stem explants of Brassica alboglabra Bailey in vitro, Plant Cell, Tissue and Organ Culture, 17 : 143$152(1989)$

16) Sharma, D. R., Kaur, R. and Kumar, K. : Embryo rescue in plants-a review, Euphytica, 89 : 325-337 (1996)

17) Takeshita, M., Kato, M. and Tokumasu, S. : Application of ovule culture to the production of interspecific hybrids in Brassica and $R a$ phanus, Japan. J. Genetics, 55(5) : 373-387 (1980)

18) Yamagishi, H., Takayanagi, K. and Ashizawa, M. : Interspecific crosses among Brassica vegetables, II. Cross-compatibility of Hakuran (Artificially synthesized B. napus) with other Brassica vegetables and production of hybrids by tissue culture, National Vegetable Research Station, A.12: 45-55(1984) (In Japanese with English summary). 